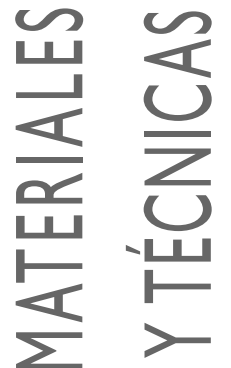

José Ignacio Álvarez Galindo, Antonio Martín Pérez y Pedro J. García Casado. Departamento de Química y Edafología, Facultad de Ciencias.

Universidad de Navarra

\title{
HISTORIA DE LOS MORTEROS
}

\section{MORTEROS PREHISTORICOS}

La cal como ligante y el mortero de cal se mencionan ya en la Biblia (Deuteronomio 5-27,2), El descubrimiento de las propiedades ligantes de la cal es tema de especulación. Algunos autores (Furlan, 1975) renuncian a datar los primeros morteros de cal, mientras que otros (Malinowski, 199I) lo sitúan muy al comienzo de la Historia del hombre, cuando éste empezó a usar el fuego para calentarse en cuevas de rocas calizas o cuando se preparaba la comida en hogares construidos de dicho material. La caliza calcinada se apagaba en contacto con la humedad o la lluvia, y el polvo resultante tenía propiedades ligantes de materiales.

Una de las primeras aplicaciones de la cal apagada fue como tinte en pinturas en cuevas (Malinowski, 199|). En Turquía, en la villa neolítica de Çatal Hüyük (6.000 a. J.C.) el "enyesado" que recubre suelos y muros, y que sirve de soporte a pinturas y al modelado de animales en los templos, es una arcilla blanca autóctona aplicada tal cual; en cuanto al mortero de tierra, utilizado para la construcción de las paredes, negro y rico en cenizas y restos de huesos, todavía no disponía de un auténtico ligante(*).

A tenor de lo reflejado en la literatura, debe diferenciarse entre las civilizaciones avanzadas de la época, situadas en el cercano Oriente y en Mesopotamia, con sorprendentes conocimientos sobre los materiales y técnicas de construcción, y el resto de civilizaciones prehistóricas de las que se tienen noticia.

Malinowski (1982 y 1991) hace referencia a esas primeras culturas. El uso de morteros sólo de cal tiene su primer empleo conocido en la Máscara de Jericó, una calavera cubierta con un emplasto de cal pulido, que data del año 7.000 a. J.C. Estas excavaciones en Jericó, la más antigua ciudad neolítica fortificada conocida, supuso una revolución en las ideas que sobre este período se tenían. Se han encontrado casas construidas con ladrillos, y con suelos hechos de un mortero de cal con superficies pulidas (llamadas "enlucidos" o "emplastes" por los arqueólogos), y, a menudo, superficies con una capa de emplasto duro coloreado. Granos de cereales y otros restos orgánicos presentes en el mortero han permitido datarlo alrededor del 7.000 a. J.C., mediante la técnica del carbono- |4. El nivel estratigráfico más profundo se ha estimado que es del 9.000 al 8.000 a. J.C.
Un reciente estudio de Reller (1992) ha encontrado en Nevali Çori (Turquía) restos de utilización de mortero de cal en pavimentos, que datan del 10.000 al 8.000 a. J.C. En excavaciones posteriores de viviendas neolíticas, situadas en el Mediterráneo Oriental y en Europa, se han encontrado suelos similares de mortero de cal, tratamientos de la superficie y técnicas de pulimentado similares. Wooley (1958) se refiere a éstos como "los pueblos de los suelos pulimentados".

Las amplias zonas de suelos de mortero en los yacimientos neolíticos indican que debieron usarse considerables cantidades de cal. La tecnología de la construcción, la calcinación de la caliza, el apagado de la cal, la mezcla del mortero, la aplicación del mismo y el refinamiento de la superficie eran indudablemente conocidos por los constructores neolíticos. Algunos investigadores piensan que la calcinación de la caliza durante el período neolítico fue la primera aplicación del fuego para la consecución de objetivos concretos, y en él sitúan el comienzo de la pirotecnología (Frierman, 197I; Gourdin y Kingery, 1976).

A pesar del evidente uso de la cal, no hay datos claros en las excavaciones que revelen la técnica de la calcinación utilizada. Sin embargo, sí que hay restos de los hornos empleados (Garfinkel, 1987). En el asentamiento neolítico de Yiftah El, en el sur de Galilea, hay suelos compuestos de una base bien compactada, un pavimento duro de mortero de cal y una superficie cuidadosamente pulida (Lamdan y Davies, 1983). Estos sistemas de construir suelos están vigentes hoy en día. La inusual calidad del mortero analizado indica una buena selección del material. La mezcla, "cal neolítica" (Frierman, 1971; Gourdin y Kingery, 1976) y una gran cantidad de piedra caliza agregada, probablemente tenían un bajo contenido en agua, lo que, por un lado, exigía una dura compactación y, por otro, era un requisito previo para el tratamiento primario de la superficie, la extensión del segundo emplaste y el pulimentado posterior (Malinowski, 1991). Han aparecido, además, mezclados en los materiales, fragmentos de los revestimientos de los hornos de calcinación; generalmente se trata de arcilla, como material más sencillo, y a veces, paja o ramas como refuerzo.

Furlan (1975) afirma que no se conoce en Europa central y septentrional ningún ejemplo de utilización de cal en la época prehistórica. Los cons- 
tructores prehistóricos se servían de arcilla cruda, con la que cubrían los suelos y las paredes de sus casas hechas de tablas de madera y de encañado. Las tapias descubiertas en las excavaciones están siempre construidas de piedras secas, y los empedrados que datan de la época de la Tène (alrededor del 450 a. J.C.) aparecen recubiertos únicamente de tierra batida. Sin embargo, en algunas excavaciones se han descubierto, no sólo en el Norte de Europa sino también en el Noreste de Auvernier, vasos de cerámica en los que los decorados grabados estaban realizados con una materia blanca y dura. Esta sustancia, tras el análisis, ha revelado ser calcárea; a veces, aparece mezclada con polvo de huesos molidos, yeso o arcilla. No ha sido posible determinar si esta pasta blanca fue aplicada originalmente como cal, a veces mezclada con otros elementos, que se carbonataría posteriormente, o si se trataba simplemente de caliza finamente triturada, y hecha pastosa por la adición de materia grasa o de otras materias orgánicas que habrían podido servir de "ligante" (o "cola").

\section{MORTEROS EGIPCIOS}

Los egipcios fueron los primeros en utilizar el yeso para el mampostado de los bloques de la pirámide de Keops (hacia 2600 a. J.C.) (Furlan, 1975). El uso de mortero de yeso queda casi exclusivamente limitado en la Antigüedad, a los morteros egipcios (Martinet, 1992; Ragai, 1988; Ragai, 1987; Ragai, 1989; Ghorab, 1986) y algún otro caso aislado señalado en la literatura (Frizot, 1975). Sólo en Grecia se ha encontrado el yeso como ligante en las paredes del Palacio de Micenas y entre los bloques gigantes del antiguo fondeadero de Kition, en Chipre (600 a. J.C.?) (Malinowski, 1982).

Se puede afirmar que fue en Egipto donde se logró en la Antigüedad el mayor conocimiento del yeso, de su preparación y aplicaciones, y también donde prácticamente se utilizó por primera vez el yeso puro como mortero. Se utilizaban diversos tipos de yesos en función de su aplicación:

\section{Yesos de colocación}

Se empleaban para facilitar la colocación de grandes bloques de piedra por deslizamiento en un plano inclinado, con el yeso como lubricante. No hay diferencias analíticas ni estructurales entre el mor- tero de las juntas verticales con el yeso de empotramiento horizontal (Martinet, 1992), de escaso espesor.

La temperatura de cocción de estos yesos fue superior a $300^{\circ} \mathrm{C}$, es decir, era un material obtenido por sobrecocción, en el que predominaba la anhidrita insoluble como constituyente esencial, y que tenía, por la presencia de esta fase insoluble no ligante, un fraguado extremadamente lento. Tenía características semejantes a un yeso muerto, que le impedían ejercer una unión rápida entre los bloques de piedra (Lucas, 1926; Martinet, 199I). En dichos yesos se ha detectado la presencia de carbonatos, a causa de la caliza presente en la roca de yeso empleada en la mezcla, y trazas orgánicas, como aditivos que podían formar parte de la receta (huevos, leche, vino, sangre animal...) (Martinet, 1992).

Los morteros de Giza presentaban en su composición yeso, calcita v sílice en la mayoría de los casos.

El origen del empleo del mortero de cal parece remontarse a la época neolítica. Este estudio ofrece una revisión histórica del desarrollo de los morteros como materiales ligantes en construcción a través de las distintas civilizaciones, todo ello desde la perspectiva de las técnicas de aplicación, de la composición de las mezclas y de la durabilidad y calidad de las mismas. Griegos y romanos perfeccionaron enormemente la técnica de mortero de cal, mientras que los egipcios dominaban la preparación) aplicación de los morteros de yeso. En el medievo la situación socioeconómica influyó de forma decisiva en que no se destacara ningún progreso técnico notable. En el siglo XVIII comienza la aparición de ligantes hidráulicos modernos, que desembocará en el siglo siguiente con el revolucionario cemento Portland.

Los morteros extraídos de la Esfinge indicaban un predominio de la fase yeso, como dihidrato $\left(\mathrm{CaSO}_{4} \cdot 2 \mathrm{H}_{2} \mathrm{O}\right)$. En morteros procedentes de la segunda pirámide y del Templo se presenta la calcita como la principal fase, $y$ en una muestra del suelo del Templo, es el cuarzo el que prevalece (Ragai, 1988; Ghorab, 1986). 


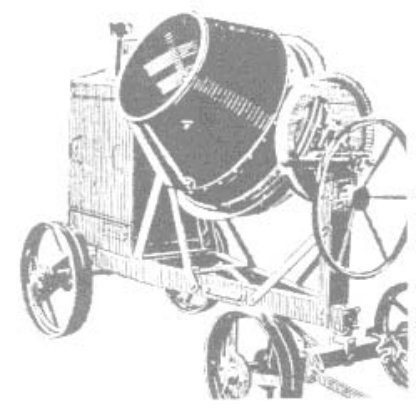

\section{Yesos de acabado}

Utilizados, tras el levantamiento de cimientos y tabiques, para el taponado de las irregularidades de las superficies, de juntas de acabado o de enlucidos de decoración. Estos ligantes, a diferencia de los yesos de colocación, no presentaban prácticamente anhidrita insoluble, sino el hemihidrato (obtenido por cocción entre $120^{\circ}$ y $160^{\circ} \mathrm{C}$ ) que le otorgaba un fraguado rápido y buena adherencia al soporte (Martinet, 1992). El porcentaje de residuo insoluble, el contenido en carbonatos y la cantidad de sales de alteración son sin embargo muy variables, por lo que pudo haber una evolución en las técnicas de fabricación (Martinet, 1992).

\section{Yesos de decoración}

Fueron empleados en Egipto ya en época ptolomeica (IV a. J.C.), como enlucidos. Precisamente será en esta aplicación donde se mantenga fundamentalmente la utilización de yeso durante la época romana y medieval (Frizot, 1975; Ashurst, 1983; Furlan, 1975).

Estos enlucidos contenían calcita en su mayoría, en cantidad notable (más del 30\% de carbonatos) en algunos casos (Martinet, 1992), sin que parezca deberse a una presencia accidental, generalmente pequeña, de la calcita en la roca de yeso, sino más bien a una adición intencionada, con objeto de blanquear la mezcla final. Esta adición de caliza a los yesos de enlucidos parece ser una práctica frecuente en la época tardía de la era faraónica (alrededor del 300 a. J.C.). También es posible que los constructores de la época ptolomeica se apercibieran, gracias a múltiples ensayos, que este añadido aportaba a la mezcla una plasticidad satisfactoria para la puesta en obra y una mejor adherencia sobre el paramento del muro a ornamentar (Martinet, 1992).

Las características de las construcciones permiten hacer algunas suposiciones sobre determinados ligantes empleados. Por ejemplo en el Templo de Amón en Karnak (Martinet, 1992) el tipo de construcción lleva a pensar en que el papel del yeso de colocación no es el de ligante. Proporciona, no obstante, una capa perfecta de reparto del peso, lo que favorece la solidez de la estructura. Esta ventaja técnica fundamental de la colocación de grandes bloques de piedra es la que explicaría su mantenimiento en todas las épocas de la historia faraónica, ya que no se conoce ningún carácter religioso atribuible al yeso para justificar su uso, al contrario de otros materiales (rocas, piedras preciosas, metales,...).

En lo referente a los enlucidos, en el Antiguo Egipto la capa de yeso era imprescindible para realizar sobre ella la decoración pictórica religiosa, puesto que, a diferencia de la caliza, sobre el gres, el material más frecuentemente empleado, no podía efectuarse sin un enlucido previo, dada la fuerte macroporosidad del soporte (Martinet, 1992).

Los yesos de Karnak poseen características sensiblemente diferentes de los yesos de la explanada de
Giza, de la Esfinge, del Templo de la Esfinge y de las Pirámides (Martinet, 1992; Ghorab, 1986; Ragai, 1988; Ragai, 1987; Ragai, 1987; Ragai, 1989).

Para justificar que los yesos de empotramiento tuviesen un papel lubricante, la explicación de la presencia de cuarzo atribuido a la carga granular del mortero, puede suponerse procedente de la fragmentación de los bloques de gres durante su colocación (Martinet, 1992).

Existen dudas sobre el método de control de la temperatura utilizada en la cocción del yeso para enlucidos $\left(120^{\circ}-160^{\circ} \mathrm{C}\right.$.), pudiendo pensarse que los egipcios habían adquirido referencias bien visuales del producto en preparación o bien de su dureza, lo que les bastaba para detener el calentamiento en el momento oportuno.

La ausencia de mortero de cal en la época faraónica sorprende, dada la cercanía de las canteras de caliza y el dominio que tenían sobre la fabricación del yeso. Puede explicarse por la elevada temperatura necesaria para la calcinación en una región en la que la madera, como fuente de energía, no era muy abundante (Martinet, 1992).

En época ptolomeica se efectúan trabajos de reconstrucción y de restauración en el Templo de Amón. A partir de este período se encuentran los primeros morteros a base de cal, testimonio de la influencia de las invasiones extranjeras (griegas y romanas) (Martinet, 1991). En definitiva, la presencia de yeso es mucho mayor en los morteros egipcios que en los europeos, independientemente de la época. Se puede descartar, también, que el mortero de cal provenga de esta civilización (Furlan, 1975).

\section{MORTEROS GRIEGOS}

Pese al gran esfuerzo de arqueólogos, científicos e historiadores, aún quedan varios aspectos por dilucidar en relación al uso del mortero de cal y a la preparación de la misma.

Puede afirmarse que el empleo de la cal como ligante tiene su origen en el período neolítico y que el uso del mortero de cal propiamente dicho corresponde a los griegos y romanos (Furlan, 1975; Malinowski, 199|), Las excavaciones realizadas atestiguan que los constructores griegos conocían los ligantes artificiales desde épocas muy remotas (Furlan, 1975), lo que corrobora la hipótesis del origen neolítico del mortero de cal. Sin embargo, la utilización del mortero de cal en Grecia para la construcción de muros es muy posterior, finales del siglo II o principio del siglo I a. J.C. (casas de Délos y de Théra) (Furlan, 1975). En anteriores construcciones, las piedras estaban unidas por un mortero hecho simplemente de tierra y de arcilla (Orlandos, 1968). Ya desde el siglo VII a. J.C., los constructores griegos hubieron de recurrir a la técnica de estucos y de revestimientos para disimular el aspecto rudo de 
ciertos materiales como la toba y la caliza, Vitruvio admira el enlucido griego, similar al mármol, en el Palacio de Croesus y el pulimentado de los emplastes, base de pinturas y frescos.

Como se ha comentado anteriormente, se conocen algunos ejemplos de la alta calidad del mortero pulido en los asentamientos del 1500 a. J.C. de Micenas y Minos, en la famosa cisterna de Micenas y en algunos edificios de Festo y Malia en Creta. Esta técnica adoptada por los griegos sería posteriormente aplicada por los romanos en sus construcciones hidráulicas (paredes, suelos, columnas en cisternas y en el interior de acueductos).

Vitruvio describe el pulimentado de morteros como una antigua técnica griega, y afirma que este cuidadoso tratamiento ayuda a impedir la contracción y las rupturas. Describe igualmente la aplicación del mortero en varias capas (3 a 6). La explicación del mecanismo y de la técnica del pulimentado del mortero, así como la razón de su aplicación en varias capas, es el resultado de recientes estudios (Malinowski, 1961 y 1979).

El pulimentado es un proceso que consiste, esencialmente, en la trituración de la cal, del carbonato - de la puzolana del mortero, para crear una estructura superficial densa, que aumente la impermeabilidad del material, acelere la carbonatación e hidratación (esto es, el endurecimiento) y mejore la fuerza y la durabilidad del material. En las construcciones para el transporte de agua el pulimentado y endurecimiento de la superficie no sólo impide la contracción y rotura del mortero, sino que también inhibe la formación de depósitos de cal en las paredes de las cisternas y acueductos debido a la mejora del flujo del agua (Malinowski, 1982).

De forma general, los morteros helénicos están hechos a base de cal y arena fina: los estucos de cal, yeso y polvo de mármol. Pero, según las necesidades, se añadían aditivos para hacer el mortero más duro y estable. En Théra, se introducía en la mezcla cal-arena polvo volcánico o "Tierra de Santorin", obtenida en la isla. Así se conseguían morteros estables al agua y puede considerarse que éste es el origen de los morteros hidráulicos modernos. Estos morteros estables al agua, así como la técnica de pulimentado de superficies, antes mencionada, fueron adoptados también por los romanos para la construcción de cisternas y acueductos.

El procedimiento de añadir a la mezcla cal-arena sustancias que confieran al mortero estabilidad ante el agua y una mayor dureza era utilizada también fuera de la citada isla, en otras partes de Grecia. Así se ha encontrado "Tierra de Santorin" en estucos que ornamentaban el Héphaïstéion de Atenas (Furlan, 1975). Ante la falta de roca volcánica, se utilizaba tejo o ladrillo triturado, como testimonia, a simple vista, la coloración rosa de ciertos enlucidos exteriores. El punto crucial en la historia del mortero es la adición a la mezcla de materiales que pudie- ran favorecer las características de la misma, y, más concretamente, el comienzo del empleo, tan extendido posteriormente, de puzolanas (primero naturales, más tarde artificiales), que en su reacción con la cal mejoran la dureza y estabilidad del mortero.

El primer uso conocido de tierra cocida (tejas, ladri\|los,...) se remonta a la época de construcción de los aljibes de Jerusalén (bajo el reinado de Salomón, en el s. X a. J.C.) (Santarelli, 1960). Este uso parece que fue introducido por obreros fenicios que conocían empíricamente las propiedades de estos materiales puzolánicos.

\section{MORTEROS ROMANOS}

Son los romanos los herederos de la tecnología de la construcción griega, y más concretamente del empleo del mortero de cal. Ya se ha señalado previamente que los romanos aplicaron la antigua técnica griega del pulimentado del mismo en sus construcciones para la conducción de agua, además del uso del mortero de cal, opus caementitium, en otras construcciones como el Panteon, el Coliseo y acueductos como el de Segovia o Pont du Garde.

Introdujeron en algunas de sus construcciones el sistema de aplicación del mortero en multicapa, como queda de manifiesto en los estudios realizados en el acueducto de Cesarea (Malinowski, 1979 y 1982), donde se aplicaron separadamente las distintas capas para favorecer el endurecimiento de cada una de ellas. En esta construcción, en concreto, una ligera capa grisácea, que contiene cenizas, es una lámina ligante; una blanca, con polvo de mármol, previene la contracción; y una capa rojiza, puzolánica, muy finamente pulimentada, de cerámica, asegura el endurecimiento en agua, la impermeabilidad y su consistencia.

Los romanos también heredaron de los griegos la técnica de añadir a la mezcla diversas sustancias que favorecían las características del mortero. Por ejemplo, con frecuencia se añadía lava ligera como agregado, como lo demuestran los morteros hallados en el Foro Romano en Ostia, en Pompeya y Herculano. La gran durabilidad de estos morteros pulidos se explica por la baja absorción y desorción de agua del agregado; al actuar de igual forma para la entrada de aire, afecta también al hinchamiento y a la contracción del mortero. Se puede señalar, por tanto, que la civilización romana mejoró los procedimientos de fabricación de la cal y las técnicas de aplicación de su mortero.

Una de las más antiguas menciones del opus caementitium se encuentra en Caton (II a. J.C.), quien describe ya una construcción ex calce et caementis. Se desconoce la fecha exacta de la introducción del mortero de cal en Roma, pero se sabe que la técnica fue utilizada en los dos últimos siglos de la República (II y I a. J.C.), que se desarrolló y generalizó rápidamente, sustituyendo a los sistemas ante-

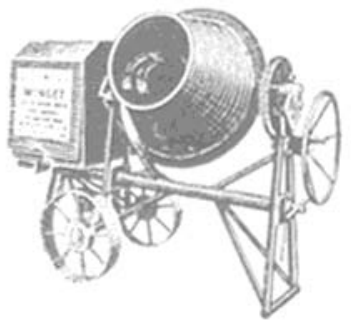




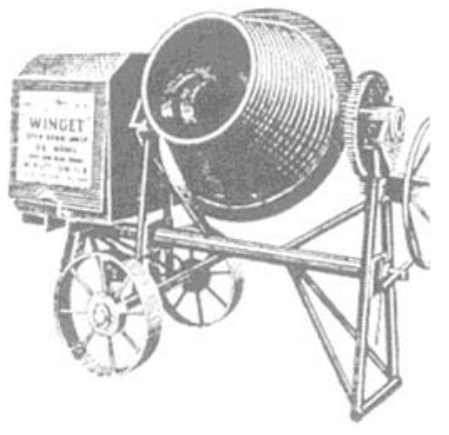

riormente utilizados, tales como el opus quadratum (gruesos bloques ajustados sin mortero) y el opus latericium primitivo, en "later crudus" o ladrillos secos.

Existen pruebas evidentes de la consistencia y durabilidad de esos morteros romanos, incluso en las condiciones más adversas. Se han efectuado análisis comparativos entre morteros romanos y actuales, sometiéndolos a condiciones ambientales desfavorables. En idénticas circunstancias, los morteros recientes sufren un daño mucho mayor que el de los romanos (Malinowski, 196I). Este hecho puede también constatarse al comparar acueductos de la época romana y construcciones marítimas actuales, como fondeaderos, y advertir su excelente estado de conservación (Malinowski, 1979).

La gran consistencia y durabilidad de los morteros romanos es citada por un gran número de autores (Malinowski, 1961, 1979, 1982; Morgan, 1988 y 1992; Furlan, 1975 y 1990; Rassineux, 1989). Parece achacarse la resistencia de los morteros, en aquellas construcciones que han mantenido un contacto directo con el agua, a la adición de sustancias que confieren al mortero propiedades hidráulicas (Malinowski, 1961 y 1979; Furlan, 1975; Rassineux, 1989), por la formación de silicatos de calcio hidratados similares a los obtenidos en el cemento moderno, bien sea por el empleo de cal con contenidos significativos de esos silicatos, o por la adición expresa de sustancias con reacción puzolánica, como tierra volcánica, tejas, ladrillos o arcillas (Rassineux, 1989).

Vitruvio es la mejor fuente para el estudio de los elementos constitutivos del mortero de cal romano (I a. J.C.). Por él sabemos que la mezcla de materiales se hacía en la proporción de una parte de cal por tres de arena, o de dos por cinco según la calidad de la arena. Pero además de estos elementos principales, menciona también el empleo de aditivos que, como se ha comentado anteriormente, ya eran usados por los griegos, tales como las cenizas volcánicas o la teja triturada, tierra cocida, etc. De hecho, los romanos practicaron a gran escala la adición a la cal de arcilla cocida y sobre todo de puzolana (roca volcánica proveniente de los yacimientos descubiertos en Pozzuoli cerca de Nápoles), lo que confiere al mortero, como ya se ha dicho, propiedades hidráulicas. En otros lugares donde no se disponía de este material se emplearon otro tipo de sustancias, "puzolanas artificiales", con similares resultados (Morgan, 1988; Rassineux, 1989).

Sin embargo, se ha pretendido profundizar más en la excelente calidad de estos morteros romanos buscando otros factores, además del uso de los aditivos anteriormente comentados. Diversos autores (Malinowski, 1961; Furlan, 1975; Furlan, 1990) señalan que, además de las características de composición, el mortero romano debe su excepcional calidad al cuidado con el que se elegían y mezclaban sus elementos constitutivos. La masa del mortero era comprimida con pilones, para llenar absoluta- mente todos los intersticios, expulsando la menor burbuja de aire. Se ha señalado también que la calidad de los morteros romanos estaba unida no sólo a los secretos de fabricación, sino, particularmente, a aditivos muy especiales.

Es posible que, para usos particulares (colocación de mosaicos, enlucidos sometidos a la acción del agua, etc.), los constructores romanos hicieran uso de aditivos tales como la albúmina y la caseína. La utilización de urea y de aceites tampoco se excluye. Sin embargo, todo induce a pensar que nunca hubo otros secretos. Pues si tales secretos hubieran existido, habrían sido transmitidos, sin duda, por la tradición. Todo lleva, por tanto, a creer que la calidad de los morteros romanos se debe esencialmente al uso de materiales convenientes (buena selección de la cal, del agregado y en casos de mezclas especiales, de otras sustancias como terracota, tejas, etc.), a la homogeneidad y correcta proporción de las mezclas, a la perfecta cocción y extinción de la cal, y a una aplicación particularmente cuidadosa (Malinowski, 1961; Furlan, 1975).

\section{MORTEROS MEDIEVALES}

Habida cuenta de las investigaciones realizadas sobre los morteros de la Edad Media, puede indicarse que en este período no hubo ningún progreso técnico notable. Hay un acontecimiento histórico previo de gran importancia en el posterior devenir de las técnicas de construcción, la caída del Imperio Romano. A partir de la misma fue difícil conservar una visión de conjunto de dicha evolución técnica, pues, a causa de las grandes invasiones, cada país, cada región, siguió en lo sucesivo su propia vía de desarrollo. Desde entonces los morteros varían también mucho de un lugar a otro, de una época a otra, incluso entre diversos edificios contemporáneos. Aunque siempre se corre un riesgo al generalizar, se puede decir que, muy a menudo, los materiales empleados son de mediocre calidad, frágiles, poco homogéneos y aplicados sin el asentamiento característico de las construcciones romanas (en el interior de los muros quedan frecuentemente numerosas cavidades) (Furlan, 1990).

Los constructores medievales, con lógicas variaciones regionales, continuaron elaborando morteros con los mismos ingredientes que lo hacían los romanos, aunque probablemente sin una selección tan cuidadosa de los materiales, y continuaron también aplicándolos de forma parecida, aunque, como ya se ha indicado, no tan esmeradamente como lo hicieron los súbditos del Imperio Romano.

Quizás convenga matizar, de entrada, la diferencia de composición química existente entre los morteros, habitualmente de cal o yeso con un agregado, y los enlucidos o emplastes, aplicados en las superficies de las paredes y que son, a veces, soportes de frescos y pinturas, con presencia de ciertos aditivos como pelos de animales (Newton, 1987). 
Los morteros medievales en Francia, en los siglos $I X, X$ y $X I$, son, generalmente, de calidad muy mediocre, a pesar de la presencia, a veces, de tejo. Hay que señalar que el tejo puede desempeñar dos funciones bien distintas. Por su naturaleza porosa, los pequeños fragmentos de tierra cocida hacen a los morteros más permeables al aire y así permiten una mejor carbonatación de la cal. Por otra parte, ciertas arcillas cocidas pueden tener una actividad puzolánica. No obstante, la "reactividad" es a menudo muy débil o nula, porque depende de la naturaleza de la arcilla y de la temperatura de cocción. Los mejores resultados se obtienen generalmente para temperaturas por debajo de la temperatura de cocción de ladrillos y tejas. En consecuencia, la adición de tejo no mejora necesariamente la calidad de un mortero (Furlan, 1975).

Se atribuye este descenso de la calidad particularmente a la pérdida de los procedimientos romanos de fabricación de la cal; esto implica su selección, la cocción y extinción, y también la homogeneidad y proporción de las mezclas. Efectivamente, se encuentran en la literatura ejemplos de este último factor, con grandes variaciones de la relación ligante/agregado (Gutiérrez-Solana, 1989), y siempre con una proporción de aglomerante muy superior a la de los morteros actuales.

Otros aspectos que parecen haber sido descuidados en la elaboración de los morteros medievales, que repercuten de forma directa en su calidad, habida cuenta de la importancia de este proceso (Malinowski, I96I, I 979 y 1982; Furlan, 1975 y 1990; Morgan, 1988 y 1992; Rassineux, 1989; Frizot, 1975), son la calidad del agregado, su granulometría, si tuvo o no tratamiento previo, y el proceso de homogeneización de la mezcla, Sin embargo, la consideración de que la disminución de calidad se debió a la variación en la preparación de la cal, subestima la importancia de la aplicación del mortero en la obra, que influye en la consistencia y durabilidad del mismo (Malinowski, 1961; Furlan, 1975).

A partir del siglo Xll las mezclas son más homogéneas y la calidad de los ligantes mejora de nuevo. A menudo, los morteros eran mezcla de gravas gruesas y cal con carbón de leña. Visto el alto contenido en carbón, puede admitirse que no se trata de una impureza, sino que este material poroso juega el mismo papel que los trozos de tierra cocida. Para los lechos y las juntas, los albañiles utilizaban arena fina y cal muy blanca (Furlan, 1975).

Al principio del siglo XIII, razones de economía impusieron a veces restricciones a los constructores. Se veían obligados a utilizar muy poca cal y la arena aparecía, a veces, mezclada con tierra; de ahí que los morteros de las catedrales de Laon, Troyes, Chalon-sur-Marne y Sées sean de muy baja calidad (Furlan, 1975). Por el contrario, en los siglos XIV y $\mathrm{XV}$, raramente se emplearon las gravas gruesas; se utilizaba sobre todo arena de planicie, que parece que en ocasiones era lavada para quitarle toda traza de arcilla y de tierra. Obvio es decir que estas medidas permitían la fabricación de un mortero de mucha mejor calidad.

Con relación a la composición de estos morteros medievales, formados por agentes ligantes naturales, como arcilla, y, en especial, agentes ligantes aéreos, cal fundamentalmente, merece consideración la incorporación de proteínas animales y otro tipo de aditivos (Furlan, 1990).

Algunos autores (Hennig y Bleck, 1968) consideran que no existe fundamento alguno para la creencia persistente de que se adicionaron proteínas animales a los morteros medievales. De hecho, para estos autores, la adición de tales sustancias como la clara de huevo, leche, caseína o sangre, no está atestiguada en la literatura histórica; por otra parte, estos investigadores han examinado muestras de morteros de los siglos XI al XVII en Alemania, y nunca han podido establecer la presencia de materias orgánicas.

Otros autores (Sickels, 1981), sin embargo, han realizado estudios comparativos entre los aditivos usados por los antiguos constructores, y sobre los que no hay dudas acerca de su empleo, y los aditivos nuevos, con el propósito de emplear estos últimos en la restauración de obras históricas. Sickels se apoya en trabajos previos, que atestiguan el empleo, ya desde la Antigüedad, de aditivos orgánicos, desde goma arábiga o tragacanto en Rodas, albúmina de huevo, queratina y caseína como aditivos comunes de los egipcios, hasta el empleo en la época de Vitruvio de jugo de higo, sangre, clara de huevo y pasta de centeno. También a finales del siglo IX se añadió sangre de buey a los morteros de la catedral de Rochester.

Alrededor del año I 200 parece comprobado el uso de cerveza, cera de abejas, huevos y la clara, jugos de frutas, gluten, malta, arroz, azúcar y orina; alrededor del año I500, se usaron cerveza, cera de abejas, sangre, huevos y claras, jugos de frutas, gluten, goma arábiga, malta, arroz, azúcar y orina (Sickels, 198I).

Parece pues tomar fuerza la idea de la adición de sustancias orgánicas, con función de ligantes, a los antiguos morteros, corroborada por los trabajos de Newton y Sharp (1987) que han demostrado la presencia de pelos de animales en enlucidos del Renacimiento. No cabe duda que el empleo de estos aditivos puede llevar aparejada la facilidad de ataque por microorganismos y una mayor solubilidad en agua (Sickels, 1981).

Sobre lo que no existen controversias, entre los distintos autores, es en lo referente a la adición de yeso o tejo, aditivos clásicos. Se ha informado que los constructores de un cantón suizo utilizaron un ligante a base de yeso, no solamente para los enlucidos, sino también para los asentamientos. Se trata de un hormigón ligado, mezclado con fragmentos y

\section{BIBLIOGRAFIA}

1. La Biblia. Deuteronomio 5 27.2.

2. Furlan, V; Bisseger, P. Les mortiers anciens. Histoire et essais d'analyse scientifique. Revue suisse d'Art et d'Archéologie 1975; 32: 1-14.

3. Malinowski, R.; Garfinkel, Y. Prebistory of Concrete. Concrete International. 1991: 62-68. 4. Malinowski, R. Ancient mortars and concretes: Aspects of their durability. Histoire of Technology 7th Annual Volume, Marsell UK. 1982: 89-101.

(*) Tomado de la Tesis Doctoral “Caracterización de morteros en monumentos bistóricos navarros" de D. José Ignacio Álvarez Galindo.

5. Reller.A.; Wilde, P. M.; Wiedemann, H. G.; Hauptmann, H.; Bonani, G. Comparative studies of ancient mortars from Giza, Egypt, and Nevali Cori, Turkey. Mat.Res.Soc.Symp.Proc. 1992; 267: 1007-1011.

6. Wooley, L. History Unearthed, E. Benin Ltd., London, 1958.

7. Frierman, J. C. Lime-Burning Precursor of Fired Ceramic. Israel Exploration Journal. 1971; 21:212-216.

8. Gourdin, W. H.; Kingery, W. D. Beginnings of Pyrotechnology. Journal of Field Archeology, MIT Press, Cambridge, 1976; 2: 133-150.

9. Garfinkel Y.Yiftab El:A Neolithic Village from the Seventh Millenium BC in the Lower Galilee. Israel Journal of Field Archeology, 1987; 14: 199-214.

10. Lamdan, M.; Davies, M. Le site de Yiftab' El (Israel).

L Antropologie, París. 1983; 87: 273-274.

11. Martinet, G.; Deloye, F X.; Golvin, J. C. Caractérisation des mortiers pharaoniques du temple d'Amon à Karnak. Bull.liaison Labo. Pet Ch. sept-oct 1992; 181: 39-45. 
12. Ragai, J. Surface and bulk properties of ancient egyptian mortars. Part lll: $X$-ray diffraction studies (b). Cement and Concrete Research. 1988; 18:9

17.

13. Ragai, J.; Ghorab, H.Y.;Antar A. Surface and bulk properties of ancient egyptian mortars.

Part II: adsorption and infrared studies. Cement and Concrete

Research. 1987; 17: 12-21.

14. Ragai, J. Surface and bulk properties of ancient egyptian mortars. Part IV. thermal studies. Cement and Concrete Research. 1988; 18: 179-184.

15. Ragai, J. Surface and bulk properties of ancient egyptian mortars. Part V: thermal studies (b). Cement and Concrete Research. 1989; 19: 42-46.

16. Ghorab, H.Y.; Ragai, J.; Antar, A. Surfare and bulk properties of ancient egyptian mortars. Part I: X-ray diffraction studies. Cement and Concrete Research. 1986; 16: 813-822.

17. Frizot, M. Mortiers et enduits peints antiques-étude technique et archéologique. Ed. Centre de recherches sur les techniques gréco-romains. Université de Dijon. 1975.

18. Lucas. A.Ancient Egyptian materials and industries, Histories and Mysteries of Man LTD, England. 1926: 468.

19. Martinet, G. Les mortiers d'époque pharaonique à Karnak. Bull.liaison Labo.Pet Ch. mars-avril 1991; 172: 157

20. Asburst, J. Mortars, plasters and renders in conservation,

Ecclesiastical Architects'and Surveyors'Association. 1983.

21. Orlandos, A. Les matériaux de construction et la technique architecturale des anciens

Grecs. París, 1968. 2 vol: 136 y ss.

22. Malinowski, R.; Slatkine, $A$ Ben Yair, M. Durability of Roman mortars and concretes for bydraulic structures at Caesarea and Tiberias. RILEM, Pra gue. 1961 piedras de diversos grosores, muy pequeños para los suelos, bastante más gruesos para los soportes, pero siempre inmersos en la masa, y no labrados, ni trabajados regularmente. Este sistema de construcción es quizás una reminiscencia de los procedimientos romanos (Furlan, 1975).

Hasta el final de la Edad Media, no comienza a generalizarse el empleo de la piedra en la construcción, ya que por razones económicas, y por tradición, este material de construcción estaba prácticamente reservado, durante siglos, a los edificios religiosos y militares. La población construía sus viviendas esencialmente con materiales combustibles, de modo que las aglomeraciones de viviendas eran frecuentemente devastadas por incendios catastróficos. Para luchar contra este peligro, las autoridades de algunos países promulgaron, desde el fin del siglo XIV, leyes para imponer la construcción con piedra. Evidentemente fue preciso que pasara tiempo para que se generalizara semejante hábito en las costumbres de los constructores (Furlan, 1975).

De esta forma, prescindiendo de las variaciones más o menos grandes en lo que concierne a la calidad, no se produce, durante la Edad Media, ningún progreso notable en la fabricación del mortero.

\section{MORTEROS MODERNOS}

Hasta el siglo XVIII no se inicia la fabricación de ligantes hidráulicos, susceptibles de endurecer bajo el agua. Los griegos, como ya se ha visto, supieron crear morteros estables al agua por medio de materiales tales como la tierra de Santorin y el tejo. Los romanos generalizaron el uso de los morteros de cal y puzolana. La mayor estabilidad en agua de las masas así obtenidas se debe a una reacción más o menos lenta entre la cal, la sílice coloidal y la alúmina, contenidas en los productos mencionados, con formación de hidrosilicatos e hidroaluminatos, cuya naturaleza es comparable a la de los productos que se obtienen por hidratación de los ligantes hidráulicos modernos (Furlan, 1975; Rassineux, 1989). El fenómeno más importante para la larga duración de los morteros romanos parece ser la protección de la matriz del ligante calcáreo debido a la baja permeabilidad del mortero a los agentes agresivos, unido al desarrollo de reacciones puzolánicas y a la formación en la superficie de una costra protectora de carbonato (Rassineux, 1989).

El descubrimiento de los ligantes hidráulicos modernos se remonta a 1756. Smeaton, encargado de la construcción del faro de Eddyston (Plymouth), se propuso encontrar una cal que pudiera resistir la acción del agua de mar. Los ensayos efectuados con una caliza de Aberthan dieron resultados positivos. Los análisis químicos demostraron la presencia de arcilla. Se llegó así a la conclusión de que "la presencia de arcilla en la caliza debe ser uno de los factores principales o el único que determina la hidraulicidad". La influencia de la tradición romana retardó probablemente el descubrimiento de los ligantes hidráulicos artificiales, ya que en la literatura romana se insiste sobre el hecho de que para obtener una buena cal hay que partir de una caliza muy pura. En consecuencia, las calizas arcillosas eran rechazadas sistemáticamente (Furlan, 1975; Rassineux, 1989).

La literatura romana (Vitruvio) indica que los morteros eran preparados por calcinación de rocas carbonatadas, apagado de la cal y su mezcla con arena. La temperatura del horno de cal para la descomposición del carbonato de calcio era de sólo $1000^{\circ} \mathrm{C}$. A esta temperatura es posible la formación de silicatos anhidros y aluminatos como $(\mathrm{CaO})_{2} \cdot \mathrm{SiO}_{2}$ y $(\mathrm{CaO})_{3} \cdot \mathrm{Al}_{2} \mathrm{O}_{3}$. Sin embargo, las rocas carbonatadas usadas entonces eran calizas puras que contenían sólo pequeñas cantidades de sílice y alúmina; por ello, los silicatos y aluminatos anhidros eran probablemente muy escasos en este tipo de cal. Además, esa cal apagada se almacenaba varios años antes de su uso. Los silicatos y aluminatos obtenidos en la calcinación se hidrataban durante el tiempo de almacenamiento y probablemente se destruían durante las operaciones de mezclado. La presencia de silicatos de calcio hidratados sólo en morteros con trozos de ladrillos sugiere, en primer lugar, que los constructores romanos usaron fragmentos de arcilla cocida, ladrillo y teja, en sustitución de la puzolana natural. La fase vítrea de puzolana es una fuente de sílice reactiva. Esta reactividad alude a la capacidad de reaccionar con la solución de cal y de formar nuevos compuestos hidratados. Así podría explicarse la formación de silicatos hidratados en este ligante, inicialmente compuesto por cal apagada. Además, la cal-puzolana o la mezcla de fragmentos de ladrillo contribuye al fraguado del mortero (Rassineux, 1989).

La localización de ettringita en los espacios libres de la textura indica su formación secundaria, después del proceso de endurecimiento. Para la formación de este mineral se necesita una fuente de sulfato. Su presencia en el mortero sugiere que este azufre se origina durante el calentamiento. La alúmina liberada durante las reacciones puzolánicas se pudo combinar para formar la ettringita.

Además, la formación de estos nuevos compuestos ocurre antes de que tenga lugar ninguna carbonatacion significativa. Los estudios de caracterización mineralógica realizados en los ligantes romanos con fragmentos de ladrillos añadidos muestran que las reacciones que tienen lugar son idénticas a las de los ligantes puzolánicos modernos. No obstante, es muy diferente la proporción de las fases específicas (Rassineux, 1989). Las fases constituidas por silicatos de calcio hidratados son muy estables en el tiempo (Malinowski, 1979; Rassineux, 1989).

Como ya se ha indicado en el apartado dedicado a los morteros romanos, parecía haber otras dos 
causas complementarias para explicar la durabilidad de estos ligantes. Una de ellas era la cuidadosa elección de los componentes del mortero, y otra la minuciosidad de la mezcla y del apisonado. Como resultado, la textura del mortero era muy compacta con una baja permeabilidad al agua y a los gases. Además, la formación de nuevos componentes hidratados debidos a las reacciones puzolánicas, disminuía la porosidad de la matriz del mortero.

Hacia 1812, Vicat estudia las mezclas de calizas puras y de arcillas, y demuestra definitivamente que las propiedades hidráulicas dependen de los compuestos que se forman durante la cocción entre la cal y los constituyentes de la arcilla. En efecto, por la acción del calor, hay primero una deshidratación de la arcilla, luego una descomposición de la caliza y por fin la combinación entre la cal, la silice y los óxidos de hierro y aluminio, originando algunos silicatos de calcio hidratados (CSH), con las propiedades antes citadas (Furlan, 1975). Según el contenido en arcilla, la temperatura y el tiempo de cocción, la reacción es más o menos completa y los productos obtenidos más o menos hidráulicos.

Los primeros ligantes así fabricados tenían muy a menudo las características de los cementos rápidos actuales. Eran ricos en aluminatos, generalmente, y por ello caracterizados por un fraguado muy rápido, no por desecación del mortero y carbonatación de la cal, sino por la reacción de los aluminatos y silicatos con el agua. Puede, por tanto, tener lugar al abrigo del aire. Los trabajos de Vicat, separándose del empirismo de sus predecesores, constituyen una base científica para la fabricación y empleo de las cales hidráulicas (Ashurst, 1983).

Las cales hidráulicas pueden ser consideradas como productos intermedios entre la cal hidratada y el cemento Portland actual. Es más, con los constituyentes hidráulicos, las cales presentan siempre un contenido elevado en cal libre y, por ello, deben ser sometidas a extinción. Esta operación, que consiste en hidratar el óxido de calcio libre, debe hacerse con una cantidad moderada de agua, para evitar la hidratación de los constituyentes hidráulicos, proceso que era ya conocido por los precursores de Vicat (Furlan, 1975).

\section{MORTEROS ACTUALES}

En I81 I, James Frost patenta un cemento artificial obtenido por calcinación lenta de caliza molida y arcilla, anticipándose al proceso que después llevó al establecimiento de algunos cementos hidráulicos "artificiales", el más famoso de los cuales se conoce como "Portland", por su supuesta apariencia y similitud con la roca caliza del mismo nombre. El comienzo del siglo XIX conllevó como hemos visto muchos experimentos e investigaciones sobre estos materiales, fundamentalmente por Vicat (Ashurst, 1983).
Joseph Apsdin, un albañil de Wakefield, patenta en 1824 un cemento "tan duro como la piedra Portland". Este es el origen del primer tipo de cemento Portland. Apsdin lo preparaba desmenuzando y calcinando la caliza, mezclando la cal resultante con arcilla y tierra y luego hidratando la mezcla cuidadosamente. A continuación calcinaba la mezcla, la desmenuzaba y la calcinaba por segunda vez, con lo que se desprendía el ácido carbónico residual. Como se empleaban temperaturas bajas, la calidad del cemento no podía ser alta (Furlan, 1975; Ashurst, 1983).

En 1838, el hijo de Apsdin, William, fabricó cemento en Gateshead, para la construcción de un tunel bajo el Tamesis con resultados más satisfactorios. Quizás fue que la calcinación se llevó a cabo a temperaturas más altas (Ashurst, 1983). A partir del trabajo de Johnson en Rochester, se obtuvo el cemento Johnson. El descubrimiento de Johnson consistió en que el clinker obtenido por fusión parcial de los elementos constitutivos de la primera materia sobrecalentada, y que hasta entonces se había tirado siempre como desecho inutilizable, da resultados mucho mejores que el cemento habitual, a condición de ser finamente triturado.

Los cementos producidos a partir de 1850 lo fueron con métodos modernos, moliendo la cal y la arcilla en un molino húmedo y calcinando la mezcla a temperaturas entre $1300^{\circ}$ y $1500^{\circ} \mathrm{C}$. La caliza se convierte así en cal viva, que se une químicamente con la arcilla formando un clinker de cemento Pórtland. Después de volver a moler y calcinar, el clinker blanco caliente se deja enfriar y se añade una pequeña cantidad de yeso para prolongar el tiempo de fraguado.

La Exposición Universal de 1851, permitió una demostración del nuevo producto, lo que le dio una gran publicidad. Desde ese momento, la mayor parte de los fabricantes de ligantes practican la calcinación a alta temperatura, y la cal fue reemplazada progresivamente por el cemento.

Las principales objeciones al uso de cales hidráulicas, cementos naturales y especialmente cemento Portland se basan en su alta resistencia, su carácter más bien impermeable y el riesgo de transferencia de sales solubles, en concreto sales de sodio, que alteran los materiales de construcción (Furlan, 1975; Ashurst, 1983).

Desde el final del siglo XIX, los principios generales de la fabricación del cemento Portland no han cambiado apenas. Sin embargo, se ha asistido a una evolución técnica y científica muy importante, que ha llevado a la preparación de ligantes aplicables a situaciones muy específicas, que han abierto un enorme campo en la investigación de estos materiales.
23. Malinowski, R. Concretes and mortars in ancient aqueducts. Concrete International. 1979; 1: 66-76.

24. Santarelli, L. Elementi di chimica del cemento. Milano, 1960. 25. Morgan, G. C.A survey of Romano-British wallplaster. Journal of the Oil and Colour Chemists'Association. 1988; 12. 417-18 y 428.

26. Morgan, G. C. Finds from the imperial west. The arcjaeological inferences of wallplaster and mortar analysis. 1992, inédito. 27. Furlan, V. Causes. mechanisms and measurement of damage in cultural heritage materials. The state of the artMortars, bricks and renderings. Advanced workshop "Analytical Methodologies for the Investiga tion of Damaged Stones" Pavia (Italy), 14-21 september, 1990. 28. Rassineux, F; Petit, J.C.; Meunier, A.Ancient analogues of modern cement: calcium bydrosilicates in mortars and concretes from Gallo-Roman Thermal Baths of Western France.

J.Am.Ceram.Soc. 1989; 72 (6): 1026-32.

29. Newton, R. G.; Sharp, J. H.An investigation of the chemical constituents of some renaissance plasters. Studies in Conservation. 1987; 32: 163-175.

30. Gutiérrez-Solana, F; Jáuregui, M.; Bobigas, R.; Sarabia, P. Análisis de morteros medievales de dos castillos de Cantabria/España. Materiales de Construcción. 1989; 39 (213): 37-45.

31. Henning, E.; Bleck, R. D. Mörteluntersuchungen an mittelalterlichen Bauwerken. Thüringen, Ausgrabungen und Funde. 1968, 13 (5): $24-27$.

32. Sickels, L. B. Organics vs. synthetics: their use as additives in mortars. Mortars, Cements and Grouts used in the Conservation of Historic Buildings, Symposium ICCROM. 1981: 2552. 